\title{
Giant mucinous cystadenoma: a case report
}

\author{
Chipo Gwanzura*, Annie Fungai Muyotcha, Thulani Magwali, Zvavahera Mike Chirenje and \\ Mugove Gerald Madziyire
}

\begin{abstract}
Introduction: Giant ovarian cysts are rarely described in the literature, owing to the availability of advanced imaging technologies in developed countries leading to early treatment. In resource-limited settings, various factors lead to late presentation.

Case presentation: We present a case of a 48-year-old black African woman with a giant mucinous cystadenoma who presented to a tertiary hospital with massive abdominal distention 5 years after being referred from a district hospital for the same problem. Surgical management resulted in fatal complications.

Conclusions: The surgical management of these huge tumors is associated with many life-threatening complications. Transvaginal ultrasound should be used in resource-limited settings to delineate ovarian masses. Community health workers must be involved in scouting and follow up of community members with unusual abdominal swellings in developing countries to avoid delays in care.
\end{abstract}

Keywords: Giant mucinous cystadenoma, Resource-limited, Health-seeking behavior

\section{Introduction}

Tumors of the ovary presenting with diameters greater than $10 \mathrm{~cm}$ are referred to as giant ovarian cysts [1]. These are rarely seen in high-income countries and consequently are rarely described in the literature, owing to availability of resources and advanced imaging technologies leading to early diagnosis of small or medium-sized tumors [2].

These tumors are generally asymptomatic at early stages, causing symptoms only after reaching enormous dimensions, and consequently are diagnosed late in lowand middle-income countries (LMICs) [1]. Compressive symptoms or a visible abdominal mass are the most frequent presenting complaints [2].

The surgical management of these masses is associated with many life-threatening complications, which arise predominantly after surgery owing to rapid changes in body circulation, and with pulmonary edema. The former include severe hypotension, increased venous return, cardiac failure, respiratory failure, and intestinal distention [2].

We report a case of a 48-year-old woman with a giant mucinous cystadenoma who presented with massive abdominal distention and whose surgical management resulted in fatal complications. We aim to remind

* Correspondence: chipo.gwanzura@gmail.com

Department of Obstetrics and Gynecology, College of Health Sciences, University of Zimbabwe, P.O. Box A178, Avondale, Harare, Zimbabwe clinicians of the challenges in diagnosing, managing, and precautions to be taken when performing surgery for patients with giant ovarian cysts.

\section{Case presentation}

A 48-year-old, para 5, postmenopausal black African woman who was human immunodeficiency virus (HIV)-negative presented to our casualty department with a 5-year history of progressive abdominal swelling. Five years prior to presenting, which was 1 year before she reached menopause, she had noticed that her abdomen was gradually distending. Her symptoms were associated with constipation, feeling of incomplete rectal emptying, early satiety, vomiting, and urinary frequency and urgency. She did not have any chronic illnesses and had a negative personal and family history of ovarian, uterine, bowel, and breast cancers. She was not receiving any medication prior to this presentation. She had delivered five children by cesarean section, and they were all alive and well. She lived in a rural area and was a subsistence farmer. She did not smoke and did not drink alcohol.

She had ascitic taps three times in 1 week at a district hospital before referral to a higher-level hospital because of recurrent reaccumulation of ascites. A transabdominal ultrasound scan (USS) showed generalized ascites with a

(c) The Author(s). 2019 Open Access This article is distributed under the terms of the Creative Commons Attribution 4.0 International License (http://creativecommons.org/licenses/by/4.0/), which permits unrestricted use, distribution, and 
thick fluid with septa, as well as bilateral mild hydroureter and hydronephrosis. Again, the ascites was drained twice. One month later, she underwent computed tomography $(\mathrm{CT})$, which showed a large predominantly cystic lesion that occupied almost the entire abdominal and pelvic cavities, which were distended, causing a marked mass effect on surrounding organs and bowel. The lesion had areas of internal septation predominantly on the right flank with no features of metastatic disease. Tumor markers measured during this admission are shown in Table 1.

The patient was referred to a tertiary hospital but only went 5 years later. Upon admission, she had marked temporal wasting, with bilateral pitting lower limb edema extending to her sacrum. She had a normal breast examination. Her blood pressure was elevated at $167 / 93 \mathrm{mmHg}$, with tachycardia of 150 beats/min. Her body temperature was $36.8{ }^{\circ} \mathrm{C}$. She had equal air entry bilaterally, and her cardiorespiratory and neurological systems were normal. She had a lower midline scar with massive abdominal distention that was nontender and had a positive fluid thrill test result (Fig. 1).

Results of investigations showed microcytic anemia with hemoglobin of $9.9 \mathrm{~g} / \mathrm{dl}$, white blood cell count of $7 \times 10^{3} / \mu \mathrm{l}$, and platelet count of $250 \times 10^{3} / \mu \mathrm{l}$. She had normal urea and electrolytes and hypoalbuminemia of $21 \mathrm{~g} / \mathrm{L}$, with results of the rest of her liver function tests being normal. Urinalysis did not show abnormalities.

Her case was discussed by a multidisciplinary team (MDT) that included gynecological oncologists, radiation oncologists, general surgeons, anesthetists, and nursing staff. The MDT considered the risks of death following hemodynamic instability and bleeding as well as the postoperative risks of deep vein thrombosis, pulmonary embolism, difficulty weaning off the ventilator, and death. The conclusion of the meeting was to take the patient for staging laparotomy despite these risks.

Preoperatively, the patient and her relatives were counseled on the possible complications. The patient received a transfusion with 2 Units (U) of packed cells (PCs). The team also contemplated drainage of the mass

Table 12013 Tumour marker results

\begin{tabular}{lll}
\hline Tumor marker & Result & Normal range \\
\hline $\begin{array}{l}\text { Lactate dehydrogenase } \\
\text { (LDH) }\end{array}$ & $477 \mathrm{U} / \mathrm{L}$ & $120-250 \mathrm{U} / \mathrm{L}$ high \\
$\begin{array}{l}\text { a-Fetoprotein (aFP) } \\
\text { Serum } \beta \text {-human } \\
\text { chorionic gonadotropin }\end{array}$ & $2.31 \mathrm{ng} / \mathrm{ml}$ & $0-6 \mathrm{ng} / \mathrm{ml}$ \\
$\begin{array}{l}\text { Carcinoembryonic } \\
\text { antigen (CEA) }\end{array}$ & $115.9 \mathrm{UlU} / \mathrm{ml}$ & $<5 \mathrm{mlU} / \mathrm{ml}$ \\
$\begin{array}{l}\text { Cancer antigen 125 } \\
\text { (CA 125) }\end{array}$ & $143.9 \mathrm{U} / \mathrm{ml}$ & $0-37 \mathrm{U} / \mathrm{ml}$ high \\
\hline
\end{tabular}

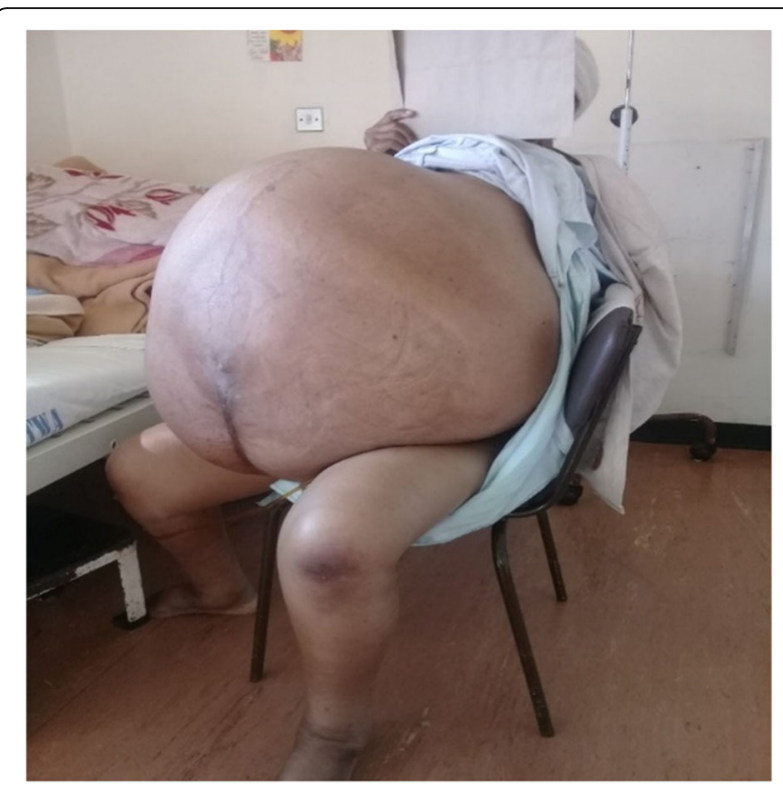

Fig. 1 Grossly distended abdomen before surgery

preoperatively but was unable to secure appropriate drains to drain the thick green fluid from the mass.

At laparotomy, through a right paramedian incision, a huge abdominopelvic mass was found filling the whole abdomen and pelvis. The liver, spleen, and hemidiaphragms looked normal. The mass was shelled out by blunt dissection (Fig. 2). The mass burst during mobilization, however, with rapid drainage of dark-colored fluid and decompression $50 \mathrm{~min}$ into the surgery. Subsequently, the mass was stripped off the anterior abdominal wall and completely excised. A total abdominal hysterectomy was done. The anterior abdominal wall was noted to have very deficient layers. Estimated blood loss was $450 \mathrm{ml}$. Anesthetically, the patient was unstable, particularly after the rapid decompression. She received a massive transfusion of $7 \mathrm{U}$ of PCs, $6 \mathrm{U}$ of fresh frozen plasma, and $4 \mathrm{~L}$ of gelafundin with $7 \mathrm{~L}$ of Ringer's lactate. The surgery lasted about $3 \mathrm{hr}$. The patient was admitted to the intensive care unit (ICU) for cardiopulmonary support.

The patient was critically ill in the ICU. On the day of admission, she had a cardiac arrest and was successfully resuscitated. She required inotropic support and ventilation. By day 5, she had developed hepatosplenomegaly, uremia, and an increased international normalized ratio. She was leaking serous fluid from the suture line, with darkening of the previously stretched skin of the anterior abdominal wall. She remained anemic with thrombocytopenia. She received a further $6 \mathrm{U}$ of PCs. She was kept on albumin and given high-protein energy feeds by the dietitian in view of her hypoalbuminemia and malnutrition. By day 6 , she was noted to have disseminated intravascular coagulopathy. She was given 


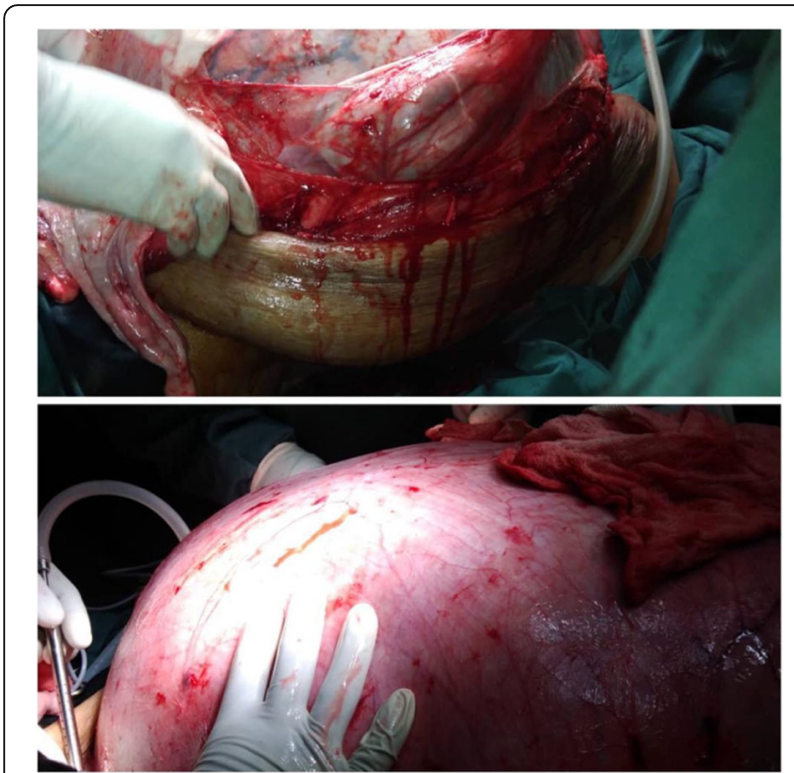

Fig. 2 Intraoperative findings upon abdominal entry

vitamin K. A pneumothorax was noted, and the cardiothoracic surgeon inserted a chest drain. She was also noted to have aspiration pneumonia following a selfextubation on the same day. By day 10, she was noted to have multiple organ failure with oliguria, falling level of consciousness, aspiration pneumonia, a gangrenous abdominal wall (Fig. 3), and coagulopathy.

She required inotropic support and ventilation. She died on day 10 after surgery. The pathology report showed a partial cystic lesion with benign epithelia of mucin-secreting columnar cells, no evidence of stromal invasion, no stratification, and no atypia and intraluminal mucin (Fig. 4). The cyst walls were necrotic with fibrinopurulent exudate. Normal ectocervical and endocervical mucosa was observed. The endometrium was inactive, and there was evidence of an anterior fibroid. This confirmed the diagnosis of benign mucinous cystadenoma. Figure 5 illustrates the sequence of events.

\section{Discussion}

We report a case of a 48-year-old woman with a giant mucinous cystadenoma who presented with massive abdominal distention and whose surgical management resulted in fatal complications. Benign mucinous cystadenomas make up the majority (81\%) of mucinous tumors. These tumors can grow to extremely large sizes and are among the largest of any recorded tumor in the body [3], as was the case with our patient. They usually occur as large multicystic masses with mucus-containing fluid, presenting commonly in women in their 20 s to 40s. The large size can itself be suggestive of mucinous histology. Our patient's presentation was pathognomic:

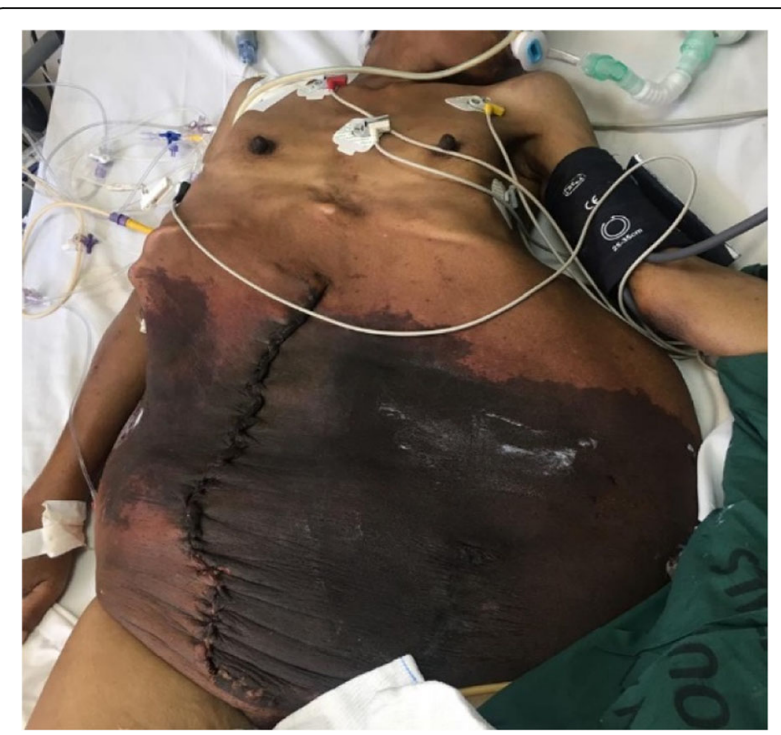

Fig. 3 Gangrenous abdominal wall postsurgery

massive abdominal distention caused by the huge mass with associated symptoms of compression of adjacent organs, constipation and rectal tenesmus from colonic compression, early satiety, and vomiting from gastric compression, frequency and urgency from increased pressure on the bladder, ureteral obstruction with the hydroureter seen on a USS, and lower limb edema from pressure on the draining veins and lymphatic vessels $[4,5]$.

This patient presented to the tertiary hospital 5 years after being referred from the district hospital. In low-resource settings, late presentation is a common feature due to socioeconomic factors as well as cultural beliefs and fear of surgery leading most to present when the symptoms become unbearable [1]. It is therefore imperative that community health workers be involved in scouting and follow-up of community members with unusual abdominal swellings.

Among the tumor markers measured in our patient, lactate dehydrogenase (LDH), carcinoembryonic antigen (CEA), and cancer antigen 125 (CA 125) were elevated. At the time the tests were done, the patient was 43 years old and premenopausal. The CA 125 assay is unreliable in differentiating benign from malignant ovarian masses in premenopausal women because of the increased rate of false-positive results and reduced specificity [6]. When CA 125 is less than $200 \mathrm{U} / \mathrm{ml}$ as in our patient, further investigations are appropriate. LDH, $\beta$-human chorionic gonadotrophin, and $\alpha$-fetoprotein should be measured in all women under age 40 with a complex ovarian mass because of the possibility of germ cell tumors [7]. In postmenopausal women, CA 125 should be used for primary evaluation because it allows the Risk of Malignancy Index of ovarian cysts to be calculated [8]. However, CA 125 should not be used in isolation, 


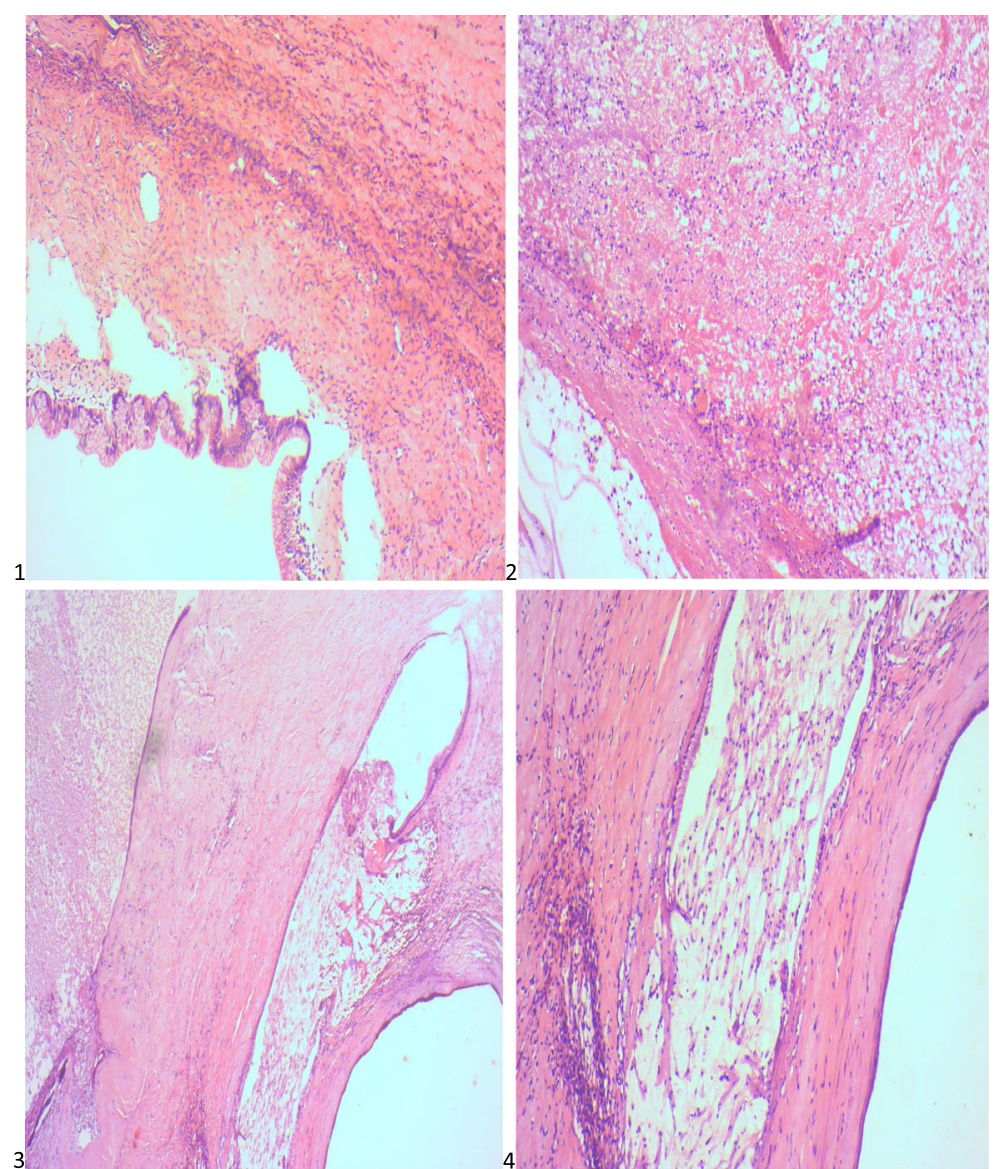

Fig. 4 Histological plates 1-4 showing partial cysts lined by mucus-secreting columnar cells with no stromal invasion, stratification, or atypia

because it is nonspecific for ovarian cancer. There is not enough evidence to suggest that panels including multiple tumor markers will offer any further advantage in the initial assessment of ovarian cysts in postmenopausal women, because all the markers show low sensitivity and wide variation in specificity when used in isolation or in combination with CA 125; hence, their routine use is not recommended [9]. The elevated CEA in our patient supported the diagnosis because it is more likely to be elevated in $88 \%$ of cases vs $19 \%$ of nonmucinous ovarian carcinomas [5].

Our patient's case displays the shortfalls of transabdominal USS as an imaging modality for the assessment of suspected ovarian masses. Although a pelvic ultrasound is the single most effective way of evaluating an ovarian mass, transvaginal ultrasonography is preferable because of its increased sensitivity over transabdominal ultrasound. A transabdominal USS should not be used in isolation; it should be used to provide supplementary information to transvaginal ultrasound, particularly when the ovarian cyst is large [10]. Our patient's case shows the utility of a CT scan if malignant disease is suspected, because it was able to define the large cystic mass.

As in our patient's case, most mucinous tumors (about $79 \%$ ) are unilateral. An algorithm was proposed in which

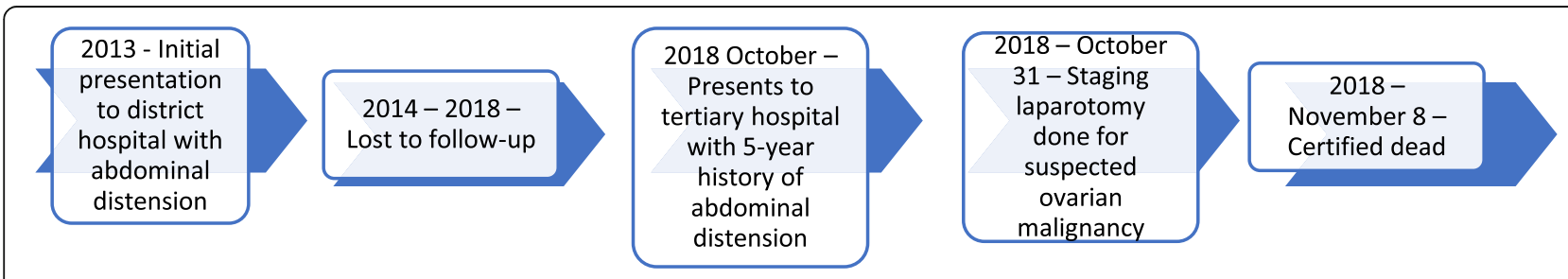

Fig. 5 Timeline showing sequence of events 
a tumor greater than $10 \mathrm{~cm}$ correctly predicted primary ovarian origin in $82 \%$ of cases [4].

Our team considered aspiration of the tumor prior to surgery. However, some authors state that aspiration of abdominal cysts should be avoided because this could cause complications such as infections, bleeding, cyst rupture, increased peritoneal adhesions, or possible dissemination of malignant cells. They therefore consider preoperative and intraoperative drainage unsafe [1]. In the past, it was thought that pseudomyxoma peritonei resulted from mucinous ovarian tumors, but now it is believed to be derived universally from appendicular low-grade (adenomatous) mucinous tumors; the ovarian involvement is secondary [3]. Other surgeons advocate controlled fluid aspiration intraoperatively to reduce hypotension and low caval reload related to sudden drop of abdominal pressure. Draining the mass is an extreme option for selected unresectable cases with high wall tension [2].

The gold standard of treatment of any suspected ovarian mass includes intact removal of the involved adnexa with intraoperative pathological evaluation, typically laparotomy, total hysterectomy, bilateral salpingo-oophorectomy, and staging procedure, including lymphadenectomy [4]. Surgery in patients with such huge masses has a high risk, as evidenced by the complications experienced by our patient. Fatal complications described in the literature include pulmonary and cardiac failure, pulmonary embolism, and sepsis. In one case with good prognosis, part of the patient preparation prior to surgery included lung preparation to improve pulmonary function postsurgery [2]. This may involve incentive spirometry to breathe deeply and exercise the lungs before and after surgery $[11,12]$.

Adequate supportive care while resecting giant ovarian masses is of the utmost importance. Postoperatively, reducing ileus, providing respiratory support, supporting abdominal wall tension, and monitoring hemodynamic parameters are key [2]. After tumor excision, an abdominal wall reconstruction might be necessary because of the laxity and redundancy of the skin [13]. We planned reconstructive surgery of the anterior abdominal wall after initial postoperative recovery because the patient was unstable at primary surgery.

When the abdomen is entered surgically, care should be taken to remove the ovary intact without spillage of the cyst contents, because rupture of a stage I mucinous ovarian carcinoma may increase its potential for recurrence. Benign mucinous cystadenomas are by definition confined to the ovary, and no further procedure is required. Therefore, had a frozen section been available, this diagnosis would possibly have enabled an oophorectomy to be performed, and the hysterectomy that contributed to additional theater time could have been avoided. Consideration also needs to be given to the fact that though benign, borderline to invasive disease may exist as a continuum in a cystadenoma. Only a limited number of sections can be evaluated intraoperatively because these tumors are quite large; hence, this may contribute to inaccuracies in diagnosis with frozen sections. Although appendectomy was previously performed for any ovarian tumor with mucinous histology, including benign lesions, current data do not support the practice [4].

The mass was not weighed, because it ruptured and was drained intraoperatively. A review of 20 cases with lesions exceeding $20 \mathrm{~kg}$ confirmed a low malignancy rate [2]. Other authors also concur, stating that huge intraabdominal tumors that almost double a patient's body weight can hardly be malignant [13].

\section{Conclusion}

Benign mucinous cystadenomas can grow to massive sizes, particularly in LMICs, and provide a huge surgical management challenge. Transvaginal ultrasound should be employed early to clearly delineate the ovaries, particularly in resource-limited nations. Community health workers in developing countries must be involved in scouting and follow-up of community members with unusual abdominal swellings to avoid delays in care.

\section{Abbreviations \\ CA 125: Cancer antigen 125; CEA: Carcinoembryonic antigen; CT: Computed tomography; HIV: Human immunodeficiency virus; ICU: Intensive care unit; LDH: Lactate dehydrogenase; LMICs: Low- and middle-income countries; MDT: Multidisciplinary team; PCs: Packed cells; USS: Ultrasound scan}

\section{Acknowledgements}

We acknowledge Dr. Shingi Bopoto for assistance with retrieving and describing the histological slides.

\section{Funding}

Not applicable.

Availability of data and materials

Data sharing is not applicable to this article as no datasets were generated or analyzed during the current study.

\section{Authors' contributions}

CG, AFM, TM, and ZMC managed the patient, wrote the manuscript, and were involved in the critical revision of the manuscript. MGM wrote the manuscript and provided independent critical review of the manuscript. All authors read and approved the final manuscript.

\section{Ethics approval and consent to participate Note applicable.}

\section{Consent for publication}

Written informed consent was obtained from the patient's next of kin for publication of this case report and any accompanying images. A copy of the written consent is available for review by the Editor-in-Chief of this journal.

\section{Competing interests}

The authors declare that they have no competing interests.

\section{Publisher's Note}

Springer Nature remains neutral with regard to jurisdictional claims in published maps and institutional affiliations. 
Received: 28 March 2019 Accepted: 28 April 2019

Published online: 14 June 2019

\section{References}

1. Yeika EV, Efie DT, Tolefac PN, Fomengia JN. Giant ovarian cyst masquerading as a massive ascites: a case report. BMC Res Notes. 2017;10(1):749.

2. Pilone V, Tramontano S, Picarelli P, Monda A, Romano M, Renzulli M, et al. Giant mucinous ovarian borderline tumor. A good lesson from an asymptomatic case. Int J Surg Case Rep. 2018;50:25-7.

3. Levine DA, Dizon DS, Yashar CM, et al. Handbook for principles and practice of gynecologic oncology. 2nd ed. Philadelphia: Lippincott Williams \& Wilkins; 2015.

4. Brown J, Frumovitz M. Mucinous tumors of the ovary: current thoughts on diagnosis and management. Curr Oncol Rep. 2014;16(6):389.

5. Frumovitz M, Schmeler KM, Malpica A, Sood AK, Gershenson DM. Unmasking the complexities of mucinous ovarian carcinoma. Gynecol Oncol. 2010;117(3):491-6.

6. Zurawski VR Jr, Orjaseter H, Andersen A, Jellum E. Elevated serum CA 125 levels prior to diagnosis of ovarian neoplasia: relevance for early detection of ovarian cancer. Int J Cancer. 1988;42(5):677-80.

7. Deligeoroglou E, Eleftheriades M, Shiadoes V, Botsis D, Hasiakos D, Kontoravdis A, et al. Ovarian masses during adolescence: clinical, ultrasonographic and pathologic findings, serum tumor markers and endocrinological profile. Gynecol Endocrinol. 2004;19(1):1-8.

8. Tingulstad S, Hagen B, Skjeldestad FE, Onsrud M, Kiserud T, Halvorsen T, et al. Evaluation of a risk of malignancy index based on serum CA125, ultrasound findings and menopausal status in the pre-operative diagnosis of pelvic masses. Br J Obstet Gynaecol. 1996;103(8):826-31.

9. Nolen B, Velikokhatnaya L, Marrangoni A, De Geest K, Lomakin A, BastBDR92102 RC Jr, et al. Serum biomarker panels for the discrimination of benign from malignant cases in patients with an adnexal mass. Gynecol Oncol. 2010;117(3):440-5.

10. Leibman AJ, Kruse B, McSweeney MB. Transvaginal sonography: comparison with transabdominal sonography in the diagnosis of pelvic masses. AJR Am J Roentgenol. 1988;151(1):89-92.

11. Bennet $P$, Williamson $C$, editors. Basic science in obstetrics and gynaecology. 4th ed. Edinburgh: Churchill Livingstone; 2010

12. University of Wisconsin Comprehensive Cancer Center Gynecologic Oncology Program. Preparing for surgery for an ovarian mass. https://www. uwhealth.org/healthfacts/gyn-onc/5666.pdf. Accessed 21 Dec 2018.

13. Hackethal A, Brueggmann D, Turovets M, Bassaly B, Stein A, Gerber EL, et al. Removal of enormous bilateral mucinous cystadenomas of the ovaries with abdominal plastic reconstruction. Arch Gynecol Obstet. 2009;279(1):65-7.

Ready to submit your research? Choose BMC and benefit from:

- fast, convenient online submission

- thorough peer review by experienced researchers in your field

- rapid publication on acceptance

- support for research data, including large and complex data types

- gold Open Access which fosters wider collaboration and increased citations

- maximum visibility for your research: over $100 \mathrm{M}$ website views per year

At $\mathrm{BMC}$, research is always in progress.

Learn more biomedcentral.com/submissions 